\title{
Schutz, Sheherazade e o homem da rua: revisitando aspectos do jornalismo como construtor da realidade ${ }^{1}$
}

\section{Schutz, Sheherazade and the man on the street: revisiting aspects of journalism as a builder of reality}

\section{Prof. Dr. Mozahir Salomão Bruck}

Tem pós-dodutorado em Teorias do Jornalismo pela Universidade Fernando Pessoa. É doutor em Literaturas de Língua Portuguesa pela PUC Minas e Mestre em Comunicação e Cultura pela UFRJ. Pesquisador do programa de Pós-graduação em Comunicação Social da PUC Minas.

<mozahir@uol.com.br>

\section{RESUMO}

Este artigo associa revisão de natureza conceitual acerca do jornalismo como construtor da realidade à uma discussão sobre a noção de Alfred Schutz (1976) de distribuição social do conhecimento. A partir dos três tipos ideais esboçados por Schutz - o especialista, o cidadão bem informado e o homem da rua - tomouse para análise o episódio midiático em que a jornalista Raquel Sheherazade, do SBT, teceu comentários acerca de ação de populares no Rio de Janeiro, que amarraram a um poste de rua um rapaz suspeito de ter cometido furtos. A apresentadora afirmou que a ação dos "vingadores" era compreensível e que, dada a falência da segurança pública no Brasil, o cidadão tem que se defender por conta própria. $O$ fato gerou grande repercussão nas redes sociais digitais e trouxe à tona mais uma vez os debates acerca dos limites da ética e da opinião no jornalismo.

Palavras-chave: Jornalismo. Schutz . Sheherazade.

\begin{abstract}
This article combines a conceptual review of journalism as a builder of reality to the discussion of the concept of Alfred Schutz (1976) about the social distribution of knowledge. From the three ideal types outlined by Schutz - the expert, the informed citizen and the man on the street - this text took up for analysis the media the episode in which the journalist Rachel Sheherazade, SBT, commented popular action in Rio de Janeiro, when people arrested a suspicious boy of committing theft to a street pole. The journalist said that the action of "avengers" was understandable and that given the failure of public security in Brazil, citizens have to defend yourself. The fact generated great effect on online social networks and brought up once again the debate about the limits of ethics and journalism opinion.
\end{abstract}

Keywords: Journalism. Schutz. Sheherazade.

\section{Considerações táticas}

Este artigo reúne, de modo sintético, revisões de natureza conceitual resultantes de pesquisa em que o autor procura avançar na construção do

\footnotetext{
1 Artigo foi produzido a partir de pesquisa de pós-doutoramento do autor pela Universidade Fernando Pessoa (Portugal), que contou com apoio da Coordenação de Aperfeiçoamento de Pessoal de Nível Superior (Capes).
} 
conceito que até aqui designa de cenários complexos inaugurais². Tal noção forjada essencialmente a partir de conceitos como conhecimento (Schutz, 1976; Berger e Luckmann, 2004; Correia, 2005) e acontecimento (Mouillaud, 2002; Quérré e França, 2012; e Traquina, 2003) - pretende melhor perceber os modos de (re)ação do jornalismo em contextos de surgimento e desenvolvimento de circunstâncias/situações complexas que impactam a sociedade. Na primeira fase da pesquisa, a empiria que suportou nossas reflexões foi o estudo da cobertura jornalística sobre drogas como o crack no Brasil e o ecstasy em Portugal, além de referenciar-se também em estudos do campo do jornalismo sobre os modos como a Aids, desde o seu surgimento, foi abordada em jornais brasileiros e portugueses.

Nesta empresa revisional, valemo-nos do conceito de distribuição social do conhecimento, de Schutz (1976), como balizador de nossa discussão, destacadamente as reflexões do autor presentes em The well-informated citizen, em que o fenomenologista austríaco esboça, a partir de seus conceitos de sistemas de relevância e quadros de tipificação, três categorias ideais que nos pareceram efetivas para esta reflexão: o especialista, o cidadão bem-informado e o homem da rua. Nosso entendimento é de que tais tipificações permitem tensionar, por meio de suas distintas configurações e modalizações narrativas, o campo do jornalismo a partir de sua efetiva potência como vetor de construção do conhecimento da vida cotidiana.

Assim, o que ora apresenta-se é uma interlocução com teóricos de reconhecida relevância do campo jornalístico 3 como Nelson Traquina, João Carlos Correia, Eduardo Meditsch e Carlos Alberto de Carvalho, entre outros, com os quais foram discutidos temas atuais importantes que atravessam o campo

2 Em sua formulação inicial, apresentamos o conceito dos cenários complexos inaugurais como possibilidade para se pensar e buscar melhor compreender os modos de (re)ação do jornalismo em contextos de surgimento e desenvolvimento de circunstâncias/situações complexas que impactam a sociedade. Tais contextos, marcados pelo ineditismo, estabeleceriam novos parâmetros de compreensão e de abordagens de tais temas/assuntos, provocando, no tecido social, novos paradigmas de comportamento individual e coletivo e, muitas vezes, reorientando as relações sociais. Diante de novos quadros de realidade e de suas exigências de explicação, o trabalho jornalístico tenderia a se desenrolar em circunstâncias de instabilidade, em função de incertezas, generalizações e mitificações - que se instalam nas lacunas abertas pela impossibilidade inicial de melhor compreensão de tais processos. Para tanto, realizou-se um estudo da cobertura da imprensa acerca da droga crack no jornal Estado de Minas (Belo Horizonte) e do ecstasy no jornal Público (Portugal) e, posteriormente, um estudo comparativo de pesquisas sobre a cobertura da imprensa acerca da Aids no Brasil (Carlos Alberto Carvalho,2009) e em Portugal (Nelson Traquina,2003).

3 As entrevistas foram realizadas por e-mail nos meses de Março e Abril de 2014, durante o estágio de pós-doutoramento do autor na cidade do Porto. No total, foram ouvidos 12 pesquisadores brasileiros e portugueses, como parte do pós-doutorado do autor em Portugal. 
teórico do jornalismo, a saber, o jornalismo como forma de conhecimento, sua contribuição para a construção da realidade cotidiana e a reconfiguração do jornalismo na contemporaneidade. $E$, a partir da sociologia compreensiva de Schutz (1976), detivemos nosso olhar sobre o episódio midiático que gerou forte repercussão, em especial nas redes sociais, e que envolveu a jornalista Rachel Sheherazade que, em 04 de fevereiro de 2014, durante a apresentação do telejornal SBT Brasil, do Sistema Brasileiro de Televisão, teceu comentários acerca de ação promovida por populares no Rio de Janeiro, que prenderam com uma corrente a um poste de rua um rapaz suspeito de ter cometido furtos.

Atuando como uma espécie de âncora do telejornal, Sheherazade, conhecida por seus comentários polêmicos e manifestados, geralmente, com um viés conservador e em tom moralista, afirmou que a ação dos "vingadores" era compreensível e que dada a falência da segurança pública no Brasil, o cidadão tem que se defender por conta própria. No estudo deste caso, recorremos também à noção de Schutz (1976) sobre o conhecimento socialmente aprovado para refletir sobre aspectos da legitimidade e da autoridade do discurso jornalístico.

\section{Jornalismo como forma de conhecimento}

Em Um Discurso sobre as ciências, Santos (2010) nos alerta para o fato de que em períodos de transição, difíceis de entender e percorrer, "é necessário voltar às coisas simples, à capacidade de formular perguntas simples". Santos preocupava-se com os evidentes sinais de desordenamentos e reordenamentos em relação ao conhecimento em um contexto de perplexidade do campo científico no final do século XX. Para o pensador, vivemos um período em que perdeu-se a confiança epistemológica e que 'instalou-se em nós uma sensação de perda irreparável tanto mais estranha quanto não sabemos ao certo o que estamos em vias de perder". No contraponto desta sensação, nos alerta Santos, pode ser que esta seja apenas uma cortina de medo por trás da qual se escondem as novas abundâncias da vida individual e coletiva, além da perplexidade de "não sabermos o que abundará em nós essa abundância" (Santos, 2010, p.8).

No campo do jornalismo, seja na atividade profissional ou no meio acadêmico e seus constantes reenquadramentos e reformulações teóricas, as noções sobre o real e a realidade já há muito se tornaram uma questão visceral. No entorno dela, outros aspectos não menos agudos: a vetorização atualizante da notícia, a verdade como pressuposto ético, as contratações de leitura efetivadas com o público, as modalizações e enquadramentos que, 
por si só, perspectivam e tensionam o acontecimento que o jornalismo elege como noticiável. E se entende o conhecimento, nessa tentativa de conhecer o real - o ocorrido - por meio das técnicas e linguagens que lhe são próprias, como modos ou perspectivas de apreendê-lo, a questão torna-se ainda mais complexa e multifacetada.

Mas façamos aqui o exercício proposto por Santos (2010): por que a discussão sobre o jornalismo como forma de conhecimento parece se bifurcar levando mesmo a pontos divergentes, quando não antagônicos, em termos das percepções sobre a informação/interpretação jornalística como partícipes efetivos nos processos individuais e, em especial, coletivos de construção social da realidade? Esta é a uma tentativa de retornar às questões fundamentais, ou, como denominadas por Santos (2010), o regresso às perguntas mais simples. Para tanto, tomamos o ponto de partida que elegemos se dá exatamente nesta encruzilhada que se observa nos estudos sobre o jornalismo como forma de conhecimento a partir da noção da sociologia do conhecimento de Berger e Luckmann (2004) - sintetizada geralmente nos estudos de comunicação pela ideia de uma construção social da realidade - e o modo como, nas décadas mais recentes veio sendo intensamente apropriada pelos estudiosos da área. Nosso ponto inicial de visada são as reflexões presentes em Schutz (1976), fonte primeira de muitas das noções de Berger e Luckmann.

Em The well-informated citizen (Schutz, 1976), o fenomenologista oferece discussões relevantes sobre a distribuição social do conhecimento, sendo que muitas delas, muito atuais mesmo tendo sido escritas há mais de seis décadas, bem cabem às reflexões sobre o jornalismo e o modo como este se faz presente na sociedade contemporânea. Segundo Schutz (1976), para o homem, prevalece a convicção de que o mundo da vida como um todo não é nem totalmente compreendido por ele mesmo e nem totalmente compreensível a qualquer um dos seus semelhantes. Existiria, assim, um estoque de conhecimento teoricamente disponível para todos, construído pela experiência prática, pela ciência e pela tecnologia como percepções garantidas. Mas não seria um estoque integrado. Há uma justaposição mais ou menos coerente de sistemas de conhecimentos que apresentam incoerências e incompatibilidades entre si. Schutz (1976) faz distinção entre o conhecimento derivado socialmente ${ }^{4}$ e o

4 Constitui-se a partir de experiências alheias, de nossos contemporâneos ou antepassados e que nos são comunicadas (articula memória e experiência). 
conhecimento socialmente aprovado ${ }^{5}$ e os esboça a partir de três tipos ideais: 0 especialista, o cidadão bem-informado e o homem da rua.

Para o pensador austríaco, o conhecimento socialmente aprovado seria fonte de prestígio e autoridade; é também a casa da opinião pública. Só é considerado um especialista ou um cidadão bem informado aquele que é socialmente aprovado como tal. Tendo obtido este grau de prestígio, as opiniões do cidadão bem informado ou do perito recebem um peso adicional no âmbito do conhecimento derivado socialmente. Apontando para o que parece considerar ser uma ética da distribuição social do conhecimento, Schutz sinaliza para uma adequação e co-responsabilidade dos atores sociais nessa distribuição:

In our time, socially approved knowledge tends to supersede the underlying system of intrinsic and imposed relevances. Polls, interviews, and questionnaires try to gauge the opinion of the man on the street, who does not even look for any kind of information that goes beyond his habitual system of intrinsic relevances. His opinion, which is public opinion as it is understood nowadays, becomes more and more socially approved at the expense of informed opinion and therefore imposes itselfas relevant upon the betterinformed members of the community. A certain tendency to misinterpret democracy as a political institution in which the opinion of the uninformed man on the street must predominate increases the danger. It is the duty and the privilege, therefore, of the well-informed citizen in a democratic society to make his private opinion prevail over the public opinion of the man on the street (Schutz, 1976, p. 134)6.

Para Schutz, muitos fenômenos da vida social poderiam ser mais bem compreendidos se fossem observados a partir da estrutura geral subjacente da distribuição social do conhecimento. Schutz, em momento logo posterior

5 Corresponde à zona de coisas admitidas, o conceito relativamente natural do mundo a partir do qual toda investigação começa e que toda investigação tem pressupostos, revela-se como o sedimento das experiências - a minha própria, bem como de outras pessoas - as quais são socialmente admitidas. 6 "No nosso tempo, o conhecimento socialmente aprovado tende a substituir o sistema subjacente de relevâncias intrínsecas e impostas. Enquetes, entrevistas e questionários tentam avaliar a opinião do homem da rua, que nem sequer olha para qualquer tipo de informação que vai além de seu sistema habitual de relevâncias intrínsecas. Sua opinião, que é o que se entende hoje em dia como sendo a opinião pública, torna-se cada vez mais socialmente aprovada em detrimento da opinião informada e, portanto, impõe-se como relevante sobre os membros mais bem informados da comunidade. Este risco aumenta com uma tendência a interpretar mal a democracia como uma instituição política em que o parecer do homem desinformado da rua deve predominar. É o dever e o privilégio, portanto, de o cidadão bem informado, numa sociedade democrática, fazer a sua opinião particular prevalecer, em termos da opinião pública, sobre a opinião do homem da rua." (Tradução do autor) 
à Segunda Guerra (1946), com a televisão ainda incipiente e a noção de mídia massiva ainda por se concretizar na sua plenitude, Schutz (1976) já enxergava riscos efetivos em relação ao modo como o que ele designava de mundo da vida poderia ser mediado, especialmente com uma tendência a fazer prevalecer, em termos da opinião pública, percepções pouco balizadas da vida social e seus contextos. No entendimento de Schutz, (1976), o cidadão bem-informado tem o dever de fazer sua opinião prevalecer em relação a do homem da rua, o que se tratava também, enfim, de um privilégio. Assim, em um dos extremos deste eixo da distribuição social do conhecimento, imaginado por Schutz, está o especialista, cujo conhecimento restringe-se a um campo limitado, mas que é claro e distinto e cujas opiniões "são baseadas em afirmações fundamentadas; seus julgamentos não são meras conjecturas ou suposições soltas" (Schutz, 1976, p. 124).

No outro extremo do eixo, encontra-se, como denominado por Schutz (1976), o homem da rua, cuja vida teria uma ingenuidade própria e relevâncias intrínsecas de seu próprio grupo. Schutz destaca que há uma tendência do homem da rua em aceitar os sentimentos e paixões como guias de suas decisões e compreensões. "Sob essa influência, ele estabelece um conjunto de convicções e pontos de vista não esclarecidos, nos quais ele simplesmente confia, desde que esses não interfiram com a sua busca da felicidade" (Schutz, 1976, p. 126). Ele não se preocuparia em entender por que algumas coisas são mais relevantes do que outras, porque zonas de irrelevâncias aparentemente intrínsecas podem esconder elementos que podem ser impostos a ele amanhã como assuntos de maior relevância; essas questões não influenciam seu agir e pensar.

O cidadão bem-informado, nesse esboço schutziano, situar-se-ia entre o tipo ideal do especialista e o homem da rua. Se por um lado, ele não possui nem pretende possuir conhecimentos especializados, por outro, ele não concorda com a imprecisão fundamental de um conhecimento prescrito ou a irracionalidade de sentimentos e paixões que não the são claras. Ele quer estar bem informado pois se ressente de formar opiniões razoavelmente fundamentadas em domínios que, como ele sabe, pelo menos indiretamente, são de preocupação para ele, embora não sejam de seu interesse mais próximo.

Para o pensador austríaco, nenhum desses tipos é, em geral, encontrado em seu estado puro na sociedade. Schutz (1976) entende que jornalistas, professores, historiadores, entre outros, representam, em geral, uma articulação entre o especialista (ou perito) e o cidadão bem-informado. O que Ihe parece ser mais relevante, porém, é como o tipo de conhecimento derivado 
socialmente, que esses atores sociais produzem e disseminam, acabam por se estabelecer como conhecimento socialmente aprovado. Schutz (1976) salienta que o poder do conhecimento socialmente aprovado é tão estendido que o que o grupo aprova - formas de pensar e agir, como costumes, modos populares, hábitos - como se fosse simplesmente um dado admitido, torna-se um elemento do conceito relativamente natural do mundo.

Schutz (1976) enfatizou ao longo da sua vida uma aproximação crescente àquilo que se poderia classificar como uma fenomenologia da atitude natural, por assim dizer, uma atitude típica dos agentes na sua participação no mundo da vida e que "implicaria em uma certa ingenuidade que se funda na suspensão de dúvidas sobre o mundo" (Correia, 2005) e aponta para uma certa ingenuidade do conhecimento", o que faz com que, tenham, diante do mundo, uma atitude pragmática, ou sejam, não questionam o que vêm, o que se passa com outros agentes, as circunstâncias das coisas e nem suas finalidades.

Correia (2005), profundo estudioso de Schutz (1976), percebe tal processo presente no modo como os media e o jornalismo se relacionam e fazem a mediação da realidade, tentando conscientemente adotar, ao descrevêla, "uma forma ingênua, pré-reflexiva, independentemente de qualquer questionamento sobre a natureza dessa realidade". O autor estabelece o que em sua visão seria a relação entre a linguagem jornalística e a atitude natural.

No contexto de condicionantes socioculturais em que vivem, os media correm um risco acentuado: circunscrevem-se à divulgação do conjunto de crenças que constituem a atitude natural de um determinado grupo, no sentido que a Fenomenologia social dava ao termo, ou seja, uma atitude perante o mundo caracterizada por um interesse eminentemente prático, e pela fé ingênua na realidade e na permanência do mundo percepcionado. A insistência na agradabilidade, a preocupação evidenciada pelo estilo jornalístico em tornar as narrativas facilmente compreensíveis e reconhecíveis aos cidadãos típicos, implica que o jornalista reflicta as tipificações e relevâncias consideradas dominantes. (Correia, 2005, p.135).

Fundamentando sua discussão a partir da noção dos sistemas de relevância de Schutz (1976), Correia (2005) salienta que um dos problemas da relação desse tipo com a realidade é que o jornalismo, por meio das notícias, apresenta, muitas vezes, um senso comum sem contexto, ou seja, "não fornece instruções acerca de 'como as coisas são' mas acerca de como elas se encaixam na ordem das coisas". E ao contar histórias acerca de como é a ordem das coisas, as instituições noticiosas oferecem, simultaneamente, uma valoração moral e uma percepção da hierarquia social que pode ser observada mesmo nos modos 
como são operados os valores-notícia, que emergem da eleição dos assuntos, fontes e entrevistados dos veículos jornalísticos. "Nesse sentido, conclui Correia, as notícias também constroem os arranjos institucionais e práticas sociais mais adequados tornando-se operadores de uma ordem convergente". (Correia, 2005, p.135).

Em entrevista ao autor deste artigo, Correia explicita seu entendimento de que o jornalismo, mesmo sendo uma força a ser relativizada, tem efetivo poder de influência em termos da construção social do conhecimento, o que coloca para o campo desafios sociais e exigências éticas que não podem ser desconsideradas.

A construção social da realidade nunca foi, do lado, de Schutz, um fenômeno entendido de forma determinista, imposto de cima para baixo, numa forma hierárquica ou piramidal. A construção social da realidade é "social" por não resultar de um sujeito solitário, mas de expectativas recíprocas e de significados partilhados. A construção de imaginários plurais é um elemento das indústrias culturais actuais. Também o jornalismo não escapou incólume à multiplicidade de realidades múltiplas pensadas por James, depois por Schutz e, hoje, por numerosos autores. (...) Logo, a importância do jornalismo neste processo é muito, para o melhor ou pior. Ou seja, algumas escolhas implicam um referencial ético associado à sociedade e o reconhecimento das diferenças dos outros. Porém, pensar o jornalismo numa lógica de objectividade pura e do olhar externo ao acontecimento em si parece cada vez mais difícil de sustentar. Da mesma maneira, recorrer a um certo relativismo para impugnar as exigências éticas de rigor não é a consequência natural desta forma de pensar que afirmei. É a consciência do carácter social e histórico da realidade que nos convoca para o rigor. (Entrevista ao autor em Abril/2014).

Este estudo, por sua vez, faz eco a outros autores que compreendem ser necessário relativizar o poder e influência que o jornalismo teria sobre os indivíduos no que diz respeito aos modos de apreensão e representação da vida quotidiana, ou por assim dizer, a construção da realidade. Atualmente, deve-se somar a atuação das chamadas mídias tradicionais - aqui nos interessando em especial os veículos jornalísticos - às redes sociais digitais e outras plataformas de conteúdo no processo de visibilidade dos acontecimentos e capacidade de agendamento das discussões pela sociedade. Para além disso, o escopo informativo/noticioso não se fixa mais hoje na narrativa de natureza jornalística, mas é reivindicada e praticada de modo alargado por outros nichos e players de informação e entretenimento. 
O pesquisador Traquina (2003) afirma perceber uma nova reconfiguração do modo como o jornalismo se faz presente na sociedade, na convivência com os novos media, mas que a transformação do acontecimento em notícia continua a ser ainda uma operação, de modo prevalente, própria do campo jornalístico.

\begin{abstract}
Antes da era do internet, o papel do jornalista (e do campo jornalístico) seria uma questão de vida ou morte: ou seria transformado em noticia e entrava no espaço público ou ficava no espaço privado das pessoas que assistiram ao acontecimento. Já não seria assim: pode viver do espaço social do mundo virtual e já não ficava no espaço privado, mas, como o caso Sterling ${ }^{7}$ demostra, a sua transformação em notícia pelas empresas jornalísticas dos media tradicionais amplia em termos sociais a sua projeção e impacto social para além do mundo virtual. Entrevista ao autor. (Entrevista ao autor em Abril/2014).
\end{abstract}

Enfim, não seria exagero dizer que o jornalismo perdeu nas últimas décadas seu status de uma legitimidade quase exclusiva de dar a conhecer as atualidades, ou se assim melhor considerar, as novidades do mundo. Ele se coloca hoje ao lado de inúmeros outros dispositivos e suportes de informação, em um mundo que parece se mostrar talvez cada vez mais informativo do que noticioso. Mas, ao mesmo tempo, seu caráter institucional, em termos de seu modo de presença na sociedade, ainda lhe confere legitimidade e autoridade para dar visibilidade, a priori, crível, aos acontecimentos do mundo.

Um caminho importante no sentido de problematizar o jornalismo como contributo para a construção do conhecimento acerca da vida cotidiana, mesmo que imediato e sabidamente perecível, vem sendo percorrido pelo pesquisador Eduardo Meditsch. O autor coloca em questão como teóricos do campo da comunicação, no caso aqui em relevo, o jornalismo, apropriaram-se de modo enviesado, e, por assim dizer, inadequado, de aspectos da sociologia do conhecimento para, ao seu modo, cristalizarem a percepção de que o jornalismo "construiria a realidade". "O que talvez esses autores não saibam, assinala Meditsch, é que o conceito de construção social da realidade (grifo do autor), criado por eles 30 anos antes, tenha se tornado uma dessas suposições enganosas ao ser aplicado aos estudos de mídia e jornalismo (Meditsch, 2010, p.20).

7 O Prof. Nelson Traquina faz referência ao escândalo, ocorrido em Abril de 2014, envolvendo o empresário da NBA, Donald Sterling, que foi banido do esporte depois que comentários racistas que teria feito foram parar na internet e recebeu grande cobertura da imprensa norte-americana. 


\begin{abstract}
Berger e Luckmann jamais colocam a mídia numa posição central nesse processo. Pelo contrário, relativizam seus efeitos no processo de socialização, na medida em que seus enunciados são escrutinados pelo indivíduo receptor, quer seja pela sua experiência direta com os fatos ou temas relatados (por suas rotinas e vínculos institucionais), quer pela consideração da opinião das pessoas que lhe são próximas e mesmo nem tão próximas, pelas redes sociais de que participa. Para os autores, naquela obra, "o veículo mais importante de conservação da realidade é a conversa" (1966, p.202), e não os meios de comunicação de massa. (Meditsch, 2010, p. 24).
\end{abstract}

Em sua releitura, Meditsch enfatiza que Berger e Luckmann não definem um "papel-chave" da mídia ou que esta teria uma centralidade ou a exclusividade em termos da construção da realidade como acabam por aparecer em vários estudos de autores que "os citam equivocadamente, antes, colocando-a num papel de mediação, articulado ao de outras "instituições especializadas na produção e comunicação do sentido". (Meditsch, 2010, p.24). Destaca que, na acepção de Berger e Luckmann, o jornalismo pode até ser incluído entre os agentes que atuam nessa construção social, "mas não como o ator único e nem mesmo o principal". (Medistsch, 2010, p.25).

Ao salientar que a "desterritorialização de conceitos pode ser problemática para a teorização sobre jornalismo" (Medistsch, 2010, p. 20), o autor busca compreender onde o conceito, na sua apropriação pelos estudiosos do jornalismo, teria se perdido ${ }^{8}$. Para Meditsch, é preciso regredir às primeiras traduções da obra de Berger e Luckmann e, em especial, ao modo como o primeiro estudo a relaciona com o jornalismo, de Gaye Tuchman, que também vem sendo traduzido e lido nas últimas décadas. Meditsch, em entrevista ao autor deste artigo em Abril de 2014, assinalou ainda que o papel do jornalismo nesse jogo de construção da realidade é certamente menos relevante que vários outros atores sociais:

A obra chama a atenção para a precedência dos processos de socialização primária e secundária nesta construção da realidade, e para a relação dialética entre o homem como produtor da sociedade, a sociedade como realidade objetiva e o homem como produto social no seio da qual esta construção precisa ser entendida. Neste arcabouço teórico, nem o jornalismo nem a mídia tem um papel central na

8 Para Medistch (2010), uma origem possível para essa apropriação desviante da noção de construção social da realidade pode ser desde a primeira tradução do livro de Berger e Luckmann para o francês e o prefácio "impressionista e subjetivista" que recebeu de Michel Mafesoli, e, na sequência, na tradução espanhola do livro de Gaye Tuchman, Making News: a study in a construction of reality, que teria adotado o pressuposto dessa onipotência do jornalismo na construção da realidade. 
construção da realidade. E a mídia, além do jornalismo, abarca também a publicidade, a ficção e outras formas de entretenimento, se pensarmos por exemplo na televisão e no rádio, que tem efeitos culturais não desprezíveis. (Entrevista ao autor em Abril/2014).

Mas, certamente, mesmo que se relativize o impacto de sua influência, o jornalismo exerce poder, em especial, por meio dos discursos pelos quais oferece modos de interpretação dos acontecimentos e julgamentos sobre os mesmos. Entendendo o jornalismo como um dispositivo de visibilidade (Bruck, 2013), o discurso que este produz e faz circular, atua, muitas vezes, de modo que o próprio enunciado do acontecimento jornalístico emerja como um acontecimento notável, não apenas obedecendo aos critérios de noticiabilidade do mundo mais comumente presentes - inversão, falha e excesso - mas, sim, do âmbito da enunciação, do simbólico. O texto jornalístico, em suas diversas configurações e formatos, aliás, assim como qualquer outra narrativa, não é, por certo, substitutivo do acontecimento, do ocorrido. Narrar é dar moldes ao que aconteceu no mundo da vida cotidiana. Para Carvalho (2012), "o discurso jornalístico está, permanentemente, marcado pelos jogos de poder e pelas disputas de significados. [...] Os argumentos são, assim, construídos tendo como pano de fundo de disputas de sentidos"(Carvalho, 2012, p.84). Esse contexto de disputa de sentidos pode ser consequência da transformação do jornalismo, de acordo com diversos autores, em um "narrador do cotidiano".

Ele [o jornalismo] é apontado como um dos principais responsáveis pela divulgação dos mais variados eventos que ocorrem em nossas complexas sociedades, e somente a partir dele é possível difundir temas e acontecimentos que, de outra forma, ficariam restritos aos seus locais de ocorrência. (Carvalho, 2012, p. 50).

Ao revisitar suas reflexões sobre o fazer jornalístico, o pesquisador Carvalho destacou o que considera ser um dos mais relevantes desafios para o profissional jornalista em sua atuação na contemporaneidade:

Falta ao fazer jornalístico - que não é científico - ficar atento, por meio de preceitos éticos mais sofisticados, ao problema de adotar enquadramentos fundamentados em pressupostos cuja inteligibilidade, até mesmo por ser muito "evidente", tem todos os indícios de indução aos erros, aos reducionismos e aos preconceitos. A considerar ainda que boa parte do nosso jornalismo atual age mesmo de má fé milimetricamente planejada. (Entrevista ao autor em Abril de 2014). 
Tais questões conectam-se com muitos dos aspectos apresentados por Schutz (1976) em The Well-informated citizen, em especial àqueles aspectos relacionados ao modo como o conhecimento e a interpretação dos fatos da vida cotidiana se distribuem na sociedade. Os discursos originados no ambiente midiático, no caso de nosso interesse, o jornalístico, reverberam e alimentam, como em ondas, tantos outros discursos, imaginários, entendimentos definidos pelos limites da capacidade de compreensão individual, mas retroalimentados fortemente também pelas visões que tendem a ser comuns, advindas das relações face a face e nos grupos sociais em que estamos instalados.

\section{Pode o jornalista falar como o homem da rua?}

Em 04 de fevereiro de 2014, o telejornal SBT Brasil, transmitido em rede nacional pelo Sistema Brasileiro de Televisão, veiculou matéria em que se mostrou um rapaz que, acusado de furto, depois de preso por populares no Bairro do Flamengo, no Rio de Janeiro, foi espancado e amarrado a um poste 9 . O rapaz acabou sendo solto e fugiu. $O$ caso foi também mostrado por várias outras emissoras e teve repercussão em todo o País. Naquela edição do telejornal, a notícia recebeu comentários da jornalista Rachel Sheherazade, do SBT e da Rádio Jovem Pan, conhecida na mídia por seus posicionamentos polêmicos e, em geral, alinhados com pensamentos mais conservadores em relação a temas políticos e sociais como segurança pública, saúde, assistência social, entre outros. No comentário, a apresentadora que atua como uma espécie de âncora do telejornal, sempre investida de uma postura oracular (Fausto Neto, 1998), afirmou que era "compreensível a atitude dos vingadores", que prenderam o suspeito de furto a um poste e o espancaram. Segundo a jornalista, na ausência do Estado, a (re)ação civil contra a violência e criminalidade é a única saída para o cidadão:

O marginalzinho amarrado ao poste era tão inocente que em vez de prestar queixa contra seus agressores, ele (sic) preferiu fugir, antes que ele mesmo acabasse preso. É que a ficha do sujeito está mais suja do que pau de galinheiro. Num país que ostenta 26 assassinatos a cada 100 mil habitantes, que arquiva mais de 80 por cento dos inquéritos de homicídio e sofre de violência endêmica, a atitude dos vingadores é até compreensível. O Estado é omisso, a polícia, desmoralizada e a justiça é falha. O que resta ao cidadão de bem que, ainda por cima, foi desarmado? Se defender, claro... O contra-ataque aos bandidos é o que eu chamo de legítima defesa coletiva de uma sociedade sem Estado, contra um estado de violência sem limite. $E$ aos defensores

9 O fato aconteceu no dia 31.01.2014 e o comentário de Rachel Sheherazade foi ao ar em 04.02.2014. 
dos direitos humanos que se apiedaram do marginalzinho preso ao poste, eu lanço uma campanha: faça um favor ao Brasil: adote um bandido. (SBT,04/02/2014).

Este comentário de Sheherazade causou grande repercussão - posts favoráveis e contrários - nas redes sociais. O texto permanece publicado até hoje no blog da jornalista ${ }^{10}$. O Sindicato dos Jornalistas do Rio de Janeiro e a Comissão de Ética da entidade divulgaram, logo em seguida, uma nota de repúdio contra a "grave violação de direitos humanos e ao Código de Ética dos Jornalistas Brasileiros" por parte de Sheherazade. Segundo a nota, "o desrespeito aos direitos humanos tem sido prática recorrente da jornalista". No entendimento do Sindicato, a apresentadora incorreu, além de uma grave falta ética, em uma verdadeira "violência simbólica", pois a jornalista teria violado os direitos humanos, o Estatuto da Criança e do Adolescente e fez apologia à violência quando afirmou achar que "num país que sofre de violência endêmica, a atitude dos vingadores é até compreensível" (Sindicato dos Jornalistas, 2014).

A despeito da avalanche de posts que o comentário de Sheherazade imediatamente gerou nas redes sociais e mesmo a repercussão em outros veículos de mídia massiva, o SBT posicionou-se sobre a polêmica apenas em 14 de abril de 2014, quando divulgou nota informando a decisão da emissora, a partir daquela data, de suspender os comentários pessoais da apresentadora, sendo que qualquer opinião no telejornalismo da emissora só passaria a ser dada pelo seu departamento de jornalismo, "na forma de editorial e identificada como tal com tarja na tela" (F5,14/04/2014). Certo é que os comentários "pessoais" de Rachel Sheherazade no SBT, em função desse vai-e-vem - sua suspensão ou não - e da intensa repercussão nas redes sociais, passaram, eles mesmos, a virar assunto na mídia: num primeiro momento, a "suspensão" durou pouco mais de um mês, pois ela foi logo autorizada pela emissora a voltar a fazê-los. Mas o SBT os proibiu novamente no mês de julho do ano passado, quando teve início o período eleitoral mais intenso na mídia. Cabe lembrar que Sheherazade atuava como jornalista em uma afiliada do SBT na Paraíba, a TV Tambaú, onde apresentava o Tambaú Notícias. Foi convidada para trabalhar na emissora SBT em rede nacional exatamente por que comentários em que denunciou "as verdades sobre o carnaval" tiveram enorme repercussão na internet, com mais de um milhão de visualizações no youtube. O comentário está ainda disponível na internet. 
Um entendimento possível é de que o comentário de Rachel Sheherazade sobre o acontecimento no bairro do Flamengo fez reverberar profundas inquietações de natureza ética e ideológica que, historicamente, assombram a mídia e, em especial, o jornalismo. Agenciadora de um conhecimento socialmente aprovado e, como diria Schutz (1976), em situação privilegiada de manifestá-lo, Rachel Sheherazade revive, no sofisticado ambiente do telejornalismo em rede, dito profissional, sério e crível, uma tradição presente durante décadas nas estratégicas midiáticas de vinculação social, em especial, da programação radiofônica, marcadas por apelos como o assistencialismo, sensacionalismo e uma demagógica visão justiceira dos conflitos e contradições sociais.

Em tom oracular, erigida em púlpito eletrônico, a especialista incorporou a fala das ruas. Nesse jogo ético-estético discursivo, que materializa um projeto identitário do telejornal e da própria emissora, a jornalista acabou por incorporar o homem da rua, de Schutz. Demagogicamente, Sheherazade se solidariza com o bárbaro e aceita os sentimentos e paixões como guias de sua compreensão do mundo. $E$, para tal, ceiva o senso comum em sua tendência dicotômica bem/ mal, de justificativas simplificadoras em nome de um enviesado desejo de fim da violência, contraditoriamente indicando o seu próprio cometimento como a solução possível para sua superação, um estímulo ao "contra-ataque aos bandidos" numa "legítima defesa coletiva" (SBT, 04/02/2014). Catarse insinuada.

Em termos da construção do conhecimento do cotidiano, mais que sobrepor e (con)fundir os tipos ideais de Schutz (1976) - o especialista, o cidadão bem informado e o homem da rua - Sheherazade parece liquidificar em ato curto circuitado as opacidades e ambiguidades do senso comum, os temores e bravatas que frutificam do conhecimento derivado socialmente, agravando-Ihes com a autoridade própria do conhecimento socialmente aprovado.

\section{Considerações finais}

As reflexões presentes neste artigo tomaram um isolado evento midiático acerca de polêmico comentário da apresentadora de um telejornal em rede do SBT que estimulou a prática do justiçamento e a reação popular como forma de combate ao crime e à violência. Isolado, mas certamente não exclusivo. Não é exagero dizer que a mídia massiva há décadas, antes mesmo do surgimento da própria televisão, abriga generosamente esse tipo de programação que, fundada na perspectivação sensacionalista e mítica, investe, 
como combustíveis da audiência, na sensação de insegurança, no medo da metrópole descontrolada e "naturalmente" violenta e cruel.

A perspectivação aqui proposta tomou como ponto de visada, a partir da sociologia do conhecimento de Schutz (1976), as noções de conhecimento socialmente derivado e conhecimento aprovado. A pergunta que nos guiou - pode o jornalista falar como o homem da rua? - remete-nos a questões estruturantes que orbitam em torno da prática do jornalismo desde sua emergência como ator social e campo de conhecimento: o cuidado ético inarredável, a informação contextualizada, a interpretação argumentada e efetivamente indicadora de pistas esclarecedoras para melhor compreensão de um cotidiano cada vez mais complexo e opacizado paradoxalmente pela super oferta de informações em todas as formas, modos e ambientes midiáticos. Ou, como nos alerta Santos (2010), tempos difíceis de entender e percorrer, repletos de desordenamentos e reordenamentos.

Um jornalista que fala como o homem da rua, no sentido que Schutz (1976) Ihe confere, subverte lugares e posturas. Acaba por, perigosamente, se deixar levar por suas paixões e sentimentos e toma a intuição e a emoção como fontes primeiras, quando não exclusivas, do que pensa e do que diz. Estandardiza o que é complexo, profetiza o caos, o fim das coisas e a vitória do mal, em um mundo, enfim, em que não vale a pena projetar, tentar organizar e acreditar na lei e na capacidade da ação solidária e coletiva. Instalado no locus privilegiado da mídia, abre mão da essência de sua natureza social ao renunciar de sua condição de especialista que contribui para a construção cotidiana do cidadão bem informado. Demagogo e dissimulado, oferece-se como um indivíduo ordinário num inquietante jogo empático de construção identitária e proposição de vinculação social que resulta numa contratação midiática marcadamente pathêmica (Amossi, 2005).

\section{Referências}

AMOSSI, Ruth. Imagens de si no discurso: a construção do ethos. São Paulo, Contexto, 2005.

BERGER, Peter L. e LUCKMANN, Thomas. A construção social da realidade. Petrópolis: Editora Vozes, 2004. 24a edição.

BLOG OFICIAL DA JORNALISTA RACHEL SHEHERAZADE. Adote um bandido. Disponível em: http://rachelsheherazade.blogspot.com.br/. Acesso em: 5 de abril de 2015. 
BRUCK, Mozahir S. Crack na imprensa: imaginários e modos de representação do jornalismo sobre o surgimento e a explosão da droga em Belo Horizonte (MG, Brasil). Artigo apresentado à Compós em 2013.

BRUCK, Mozahir Salomão e CARVALHO, Carlos Alberto. Jornalismo: cenários e encenações. São Paulo: Intermeios, 2012.

CORREIA, J.C. A teoria da comunicação de Alfred Schutz. Lisboa: Livros Horizonte, 2005.

FAUSTO NETO, Antônio. Em busca da cena primária. Copião do autor. 1998.

Jornal do SBT. Disponível no Youtube: http://www.youtube.com/ watch?v=nXraKo7hG9Y. Acesso em 08 de janeiro de 2015.

F5 - Folha on line. 14/04/2014. Disponível em http://f5.folha.uol.com.br/ televisao/2014/04/1440552-apos-polemica-sbt-corta-comentarios-pessoaisde-rachel-sheherazade-de-telejornal.shtml

MEDITSCH, Eduardo. Jornalismo e construção social do acontecimento. In: BENETTI, Marcia; FONSECA, Virgínia Pradelina da Silveira. Jornalismo e acontecimento: mapeamentos críticos. Florianópolis: Insular, 2010. p. 19-42.

MEDITSCH, Eduardo. O jornalismo é uma forma de conhecimento? In: Media e Jornalismo. Coimbra, Edições MinervaCoimbra, 1997.

MOUILLAUD, Maurice. O jornal: da forma ao sentido. Brasília: Editora UnB, 2002.

SCHUTZ, Alfred. Collected Papers, Vol. II. Studies in The Hague, Martinus Nijjoff. 1976.

SANTOS, Boaventura de S.. Um discurso sobre as ciências. Porto: Edições Afrontamento, 2010. 16 edição.

Sindicato dos Jornalistas do Rio de Janeiro. Nota de Repúdio. Acesso em 07/01/2014 em: $\quad$ http://jornalistas.org.br/index.php/nota-de-repudio-do-sindicato-e-dacomissao-de-etica-contra-declaracoes-da-jornalista-rachel-sheherazade/.

TRAQUINA, Nelson. $\mathbf{O}$ estudo do jornalismo no século XX. São Leopoldo: Editora Unisinos, 2003.

YOUTUBE. Rachel fala sobre o adolescente vítima de "justiceiros" no Rio. Disponível em : https://www.youtube.com/watch?v=unVlpQHLDwE. Acesso 
em 05 de abril de 2015.

YOUTUBE. Coragem: Jornalista fala no ar toda a verdade sobre o carnaval.

Disponível em : https://www.youtube.com/watch?v=VN6Kr5jFogY. Acesso em 05 de abril de 2015.

Recebido em: 30/4/2015

Aceito em: 19/5/2015

Endereço do autor:

Mozahir Salomão Bruck <mozahir@uol.com.br>

Rua Palmira, 528/302 - Bairro Serra

CEP: 30220-110

Belo Horizonte/MG - Brasil 